UDC 579.66:663.16:577.164.12

DOI: 10.15587/2706-5448.2021.247266

Article type «Reports on Research Projects»

\section{Nataliia Stetsenko, Valentyna Polishchuk, Olexiy Dugan}

\title{
DEVELOPMENT OF NUTRIENT MEDIUM FOR RIBOFLAVIN BIOSYNTHESIS BY EREMOTHECIUM ASHBYI A5COMYCETES
}

The object of the study is the riboflavin producer Eremothecium ashbyi Guilliermond 1935 VKPM F-340, the subject of the study is the regularities of riboflavin biosynthesis by the E. ashbyi F-340 strain under different cultivation conditions. Riboflavin is an important micronutrient that is a precursor of the coenzymes flavin mononucleotide and flavinadine dinucleotide, it is necessary for biochemical reactions in all living cells. Population growth and an increase in human needs for vitamin-fortified food and agricultural products is the reason for an increase in demand for riboflavin preparations. Considering this, it is important and economically beneficial to improve the technology for the production of vitamin B2. An important factor that affects the yield of the product is the nutrient medium. At present, the influence of agricultural waste on the biosynthesis of riboflavin is being actively studied in the world. However, not all of the studied types of raw materials are typical for the agriculture of this or that country. Therefore, in order to determine whether this direction of research is promising, it is important to check the effect on the biosynthetic activity of the riboflavin producer of the most common wastes of the domestic industry. In this work, this is done on the example of Ukraine.

In the course of the study, microbiological (surface and deep cultivation of E. ashbyi F-340), physicochemical (determination of the amount of biomass by the gravimetric method, determination of the concentration of riboflavin by the spectrophotometric method) and mathematical methods were used. The proposed media with the addition of agricultural waste, providing a higher yield of riboflavin compared to conventional media. The influence of different types of agricultural waste on the biosynthesis of riboflavin by the producer E. ashbyi F-340 was evaluated. The efficiency of using sunflower cake as a component of the nutrient medium is shown. The optimal sources of carbon for the nutrient medium with oil cake have been determined, which increases the yield of riboflavin. Due to the large amount of sunflower cake obtained in Ukraine, its use for modifying the nutrient medium in order to increase the yield of riboflavin in the future will lead to a decrease in the cost of the target product due to the use of cheap and ecological raw materials.

Keywords: riboflavin producer, Eremothecium ashbyi F-340, submerged cultivation, agricultural waste, sunflower cake.

Stetsenko, N., Polishchuk, V., Dugan, O. (2021). Development of nutrient medium for riboflavin biosynthesis by Eremothecium ashbyi ascomycetes. Technology Audit and Production Reserves, 6 (3 (62)), 53-56. doi: http://doi.org/10.15587/2706-5448.2021.247266

\section{Introduction}

Riboflavin, or vitamin B2, is an essential component of the diet of humans and animals, since it is a precursor of flavin coenzymes: flavin mononucleotide and flavinadine dinucleotide, which are involved in many redox reactions. The biotechnological method of obtaining vitamin B2 using the natural superproducer Eremothecium ashbyi [1, 2] is one of the most beneficial. Active research is underway to improve the technology for producing riboflavin. One of the main factors affecting the biosynthetic activity of a producer is the composition of the nutrient medium. It is proposed to use inexpensive and inedible waste of the oilseed industry (peanut cake, flax seeds, sesame cake, etc.) to increase the yield of riboflavin [3-5]. The use of plant materials has several advantages: environmental friendliness, prevalence, low cost and a high level of nutrient content. Usually, the lack of this raw material, its variable composition depends on the quality of the original product. It also makes it impossible to use it for the creation of pharmaceutical products, but not essential for the production of feed.

Every year, the agricultural industry becomes a source of waste that must be disposed of. Some of these wastes, namely meal, cake, bran of various plant crops are of interest for biotechnology as components of nutrient media. In agriculture, they are used as one of the ingredients of compound feed, which can significantly increase its nutritional 
value due to proteins, amino acids, vitamins and microelements contained in plant raw materials. While these wastes have found their way into the food and feed industries, in addition, they can bring even more income in biotechnology. This is a compelling reason to test the effect of these wastes on riboflavin yield. One of the main elements of the Ukrainian economy is the agrarian sector, on the example of whose waste this problem is studied.

So, the object of research is the natural producer of riboflavin Eremothecium ashbyi Guilliermond 1935 VKPM F-340. This producer does not carry the risk of transmitting antibiotic resistance genes and can be used in the production of both feed and riboflavin food applications [6, 7].

The aim of this work is to study the effect of agricultural waste on the biosynthesis of riboflavin by the producer Eremothecium ashbyi Guilliermond 1935, VKPM F-340.

\section{Methods of research}

E. ashbyi F-340 culture is maintained on liquid glucosepeptone-yeast (GPY) medium of the following composition: glucose $-1.0 \%$; peptone $-0.3 \%$; yeast extract $-0.5 \%$.

The inoculation and experimental cultivation were carried out in $250 \mathrm{~cm}^{3}$ conical flasks of $50 \mathrm{~cm}^{3}$ nutrient medium on orbital shakers at a rotation speed of $180 \mathrm{~min}$ for 7 days at a temperature of $28 \pm 2{ }^{\circ} \mathrm{C}$. The initial $\mathrm{pH}$ was set at 6.5-7.0. The inoculum was added in an amount of $1 \%$.

The cultivation was carried out on complex nutrient media, which are most often found in the literature:

- media specified in the strain passport: glucose-peptone-yeast, unhopped beer wort (330 $\mathrm{cm}^{3}$ of unhopped beer wort per $1 \mathrm{dm}^{3}$ of water);

- media with glucose, glucose-fructose syrup (GFS-10) [5, 8], molasses [4] (the amount of carbohydrates per $10 \mathrm{~g} / 1$ glucose);

- soybean environment [6];

- medium on whey;

- medium of composition: $10 \mathrm{~g} / \mathrm{dm}^{3}$ glucose, $5 \mathrm{~g} / \mathrm{dm}^{3}$ yeast extract, to which was added agricultural waste in an amount of $20 \mathrm{~g} / \mathrm{dm}^{3}$.

The amount of biomass was determined by the gravimetric method after separation from the culture liquid by filtration and drying in an oven to a stable weight at $105^{\circ} \mathrm{C}$ [9].

The study of the level of accumulation of riboflavin was carried out spectrophotometrically at $450 \mathrm{~nm}$ after preliminary hydrolysis of FAD in FMN for 12 hours in $10 \%$ trichloroacetic acid $[10,11]$. In order to release riboflavin from the biomass, the mycelium was hydrolyzed in the presence of a $6 \mathrm{~N}$ hydrochloric acid solution. The culture fluid was filtered through a paper filter and used to determine the riboflavin content.

\section{Research results and discussion}

At the first stage of the research, in order to compare the yield of riboflavin on standard and non-standard media, cultivation was carried out on the media most frequently encountered in the literature (Table 1). Selected complex media, on the one hand, are more favorable for the growth and production of biologically active metabolites from fungi than synthetic ones, and on the other hand, they are relatively cheap.

The best results were obtained by cultivating the producer on a medium with glucose-fructose syrup (GFS-10), which was also shown in earlier studies [8] and on unhopped beer wort. Riboflavin on a medium with GFS-10 is synthesized by $82.2 \%$ more than on wort. Similarly, the amount of biomass obtained with GFS-10 is $15.9 \%$ more than with beer wort.

Table 1

Accumulation of riboflavin and biomass of $E$. ashbyi F-340 on complex media

\begin{tabular}{|c|c|c|}
\hline Nutrient medium & $\begin{array}{c}\text { Riboflavin concentra- } \\
\text { tion, mg/dm }\end{array}$ & $\begin{array}{c}\text { Biomass concentra- } \\
\text { tion, } \mathrm{mg} / \mathrm{dm}^{3}\end{array}$ \\
\hline Unhoped beer wort & $77.0 \pm 2.65$ & $4.16 \pm 0.17$ \\
\hline GPY & $20.51 \pm 0.8$ & $2.55 \pm 0.19$ \\
\hline GF5-10 & $\mathbf{1 4 0 . 2 8} \pm \mathbf{0 . 8 2}$ & $4.82 \pm 0.2$ \\
\hline Glucose+YE & $21.0 \pm 0.64$ & $1.52 \pm 0.14$ \\
\hline Soybean environment & $34.93 \pm 1.75$ & $*$ \\
\hline Molasses & $14.46 \pm 0.79$ & $3.84 \pm 0.38$ \\
\hline Molasses+YE & $26.56 \pm 1.66$ & $14.19 \pm 0.4$ \\
\hline Milk whey & $5.97 \pm 0.53$ & $*$ \\
\hline Milk whey+YE & $26.26 \pm 0.77$ & $*$ \\
\hline
\end{tabular}

Note: GPY - glucose-peptone-yeast medium; GFS - glucose-fructose syrup; YE - yeast extract; ${ }^{*}$ - the concentration of biomass was not determined; the best result is in bold

To test the influence of agricultural raw materials, wastes of oil production (sunflower cake, pumpkin, red, flax, milk thistle) and food production (bran of buckwheat, rye, corn flour, fish meal) were selected. They were added in an amount of $20 \mathrm{~g} / \mathrm{dm}^{3}$ to the basic composition of the medium. The main composition of the medium was used as a control. The cultivation results are presented in Table 2 .

Table 2

Accumulation of riboflavin E. ashbyi F-340 on media with agricultural waste

\begin{tabular}{|c|c|}
\hline Environment & Riboflavin concentration, $\mathrm{mg} / \mathrm{dm}^{3}$ \\
\hline Milk thistle cake & $115.91 \pm 10.59$ \\
\hline Red cake & $145.74 \pm 6.10$ \\
\hline Pumpkin cake & $260.48 \pm 12.94$ \\
\hline Sunflower cake & $\mathbf{2 6 8 . 1 4} \pm \mathbf{1 3 . 3 4}$ \\
\hline Flax cake & $167.32 \pm 8.47$ \\
\hline Buckwheat bran & $195.76 \pm 8.72$ \\
\hline Bran rye & $219.42 \pm 10.99$ \\
\hline Corn flour & $174.32 \pm 5.59$ \\
\hline Fish flour & $205.71 \pm 10.01$ \\
\hline Control & $28.48 \pm 3.09$ \\
\hline
\end{tabular}

Note: the best score is shown in bold

All of the wastes used significantly increased the yield of riboflavin. The greatest amount of riboflavin is observed with the addition of pumpkin and sunflower cake, 9.1 and 9.4 times more than the control, respectively. In the course of cultivation, the medium with the cake acquired a dark green color, in contrast to other media, the colors of which varied from light yellow to dark brown.

For further research, the possibility of cultivating the fungus $E$. ashbyi F-340 on agar nutrient media with the 
addition of sunflower cake was tested. For this purpose, sunflower cake at a concentration of $20 \mathrm{~g} / \mathrm{dm}^{3}$ was added to the agarized GPY medium, on which the producer strain is preserved (Fig. 1).

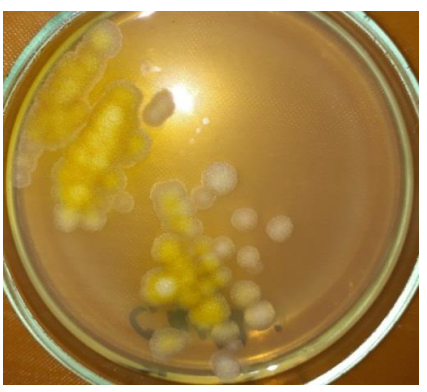

a

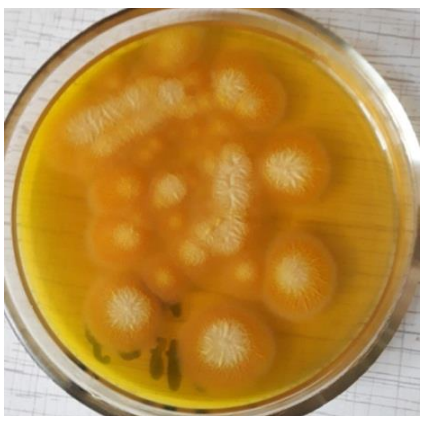

C

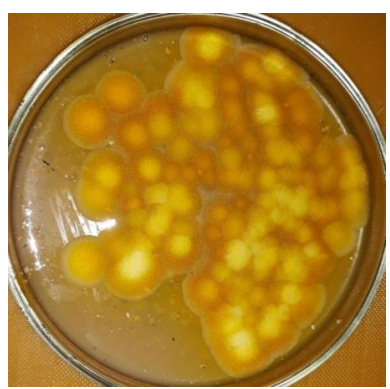

b

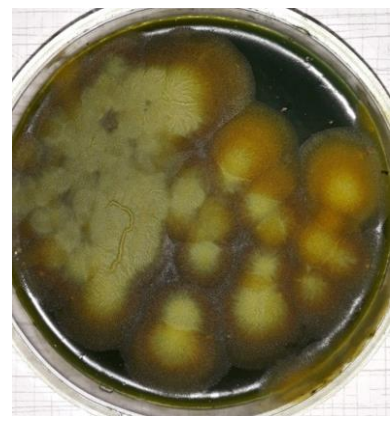

d
Fig. 1. Colonies of Eremothecium ashbyi on agar media: $a$ - GPY medium on the 6th day of cultivation; $b$ - GPY medium with the addition of $20 \mathrm{~g} / \mathrm{dm}^{3}$ of sunflower cake on the 6th day of cultivation; $c$ - GPY medium on the 10th day of cultivation; $d$ - GPY medium with the addition of $\mathrm{g} / \mathrm{dm}^{3}$ sunflower cake on the 10th day of cultivation

On the 6th day of cultivation on a medium with the addition of cake, colonies of a larger size, colored in an intense orange color, as well as pigmentation of the culture medium, are observed, while on a medium without the addition of cake, colonies of a smaller size are colored yellow or not yet colored. The intensity of the color indicates a more intense accumulation of riboflavin. On the 10th day of cultivation on a medium without cake, the colonies are colored orange, and the most agar medium becomes yellow due to the release of riboflavin from the cells. On a medium with cake, some of the colonies remain orange, but the medium itself acquires a dark green color, which may indicate the accumulation of a large amount of riboflavin.

At the next stage, the influence of the concentration of sunflower meal on the biosynthesis of riboflavin was investigated (Table 3).

The amount of riboflavin accumulated in the culture liquid increases with an increase in the concentration of cake. On a medium containing $20 \mathrm{~g} / \mathrm{dm}^{3}$ of cake, riboflavin was synthesized 8.2 times more than on the control medium. A further increase in the concentration of cake is impractical, since it leads to an increase in the concentration of riboflavin by only $5 \%$ and, at the same time, the sterilization of the nutrient medium becomes more complicated.

At the next stage, the cultivation of the producer was investigated on liquid media containing glucose, fructose, sucrose and GFS-10 as a carbon source in an amount equivalent to $10 \mathrm{~g} / \mathrm{dm}^{3}$ of glucose and $20 \mathrm{~g} / \mathrm{dm}^{3}$ of cake. The cultivation results are presented in Table 4 .
Table 3

The accumulation of riboflavin E. ashbyi F-340 on GPD medium with the addition of various concentrations of sunflower meal

\begin{tabular}{|c|c|}
\hline Nutrient medium & Riboflavin concentration, $\mathrm{mg} / \mathrm{dm}^{3}$ \\
\hline Control & $25.15 \pm 0.58$ \\
\hline Cake $4 \mathrm{~g} / \mathrm{dm}^{3}$ & $46.84 \pm 0.86$ \\
\hline Cake $10 \mathrm{~g} / \mathrm{dm}^{3}$ & $116.79 \pm 4.06$ \\
\hline Cake $16 \mathrm{~g} / \mathrm{dm}^{3}$ & $181.64 \pm 4.26$ \\
\hline Cake $\mathbf{2 0} \mathbf{g} / \mathbf{d m}^{\mathbf{3}}$ & $\mathbf{2 0 7 . 3 7} \pm \mathbf{1 . 8 0}$ \\
\hline Cake $30 \mathrm{~g} / \mathrm{dm}^{3}$ & $218.56 \pm 5.08$ \\
\hline
\end{tabular}

Note: the best score is shown in bold

The accumulation of riboflavin E. ashbyi F-340 on media with different carbon sources and sunflower meal

\begin{tabular}{|c|c|}
\hline Nutrient medium & Riboflavin concentration, $\mathrm{mg} / \mathrm{dm}^{3}$ \\
\hline $\begin{array}{l}\text { Glucose } 10 \mathrm{~g} / \mathrm{dm}^{3} \\
\text { cake } 20 \mathrm{~g} / \mathrm{dm}^{3}\end{array}$ & $151.23 \pm 3.85$ \\
\hline $\begin{array}{c}\text { GFS-10 } 20 \mathrm{~g} / \mathrm{dm}^{3} \\
\text { cake } 20 \mathrm{~g} / \mathrm{dm}^{3}\end{array}$ & $230.85 \pm 2.83$ \\
\hline $\begin{array}{c}\text { Fructose } 10 \mathrm{~g} / \mathrm{dm}^{3} \\
\text { cake } 20 \mathrm{~g} / \mathrm{dm}^{3}\end{array}$ & $198.77 \pm 5.13$ \\
\hline $\begin{array}{c}\text { Sucrose } 9.5 \mathrm{~g} / \mathrm{dm}^{3} \\
\text { cake } 20 \mathrm{~g} / \mathrm{dm}^{3}\end{array}$ & $133.46 \pm 1.81$ \\
\hline
\end{tabular}

Note: the best scare is shown in bold

It has been found that the biosynthetic activity of the E. ashbyi F-340 strain is maximal in the medium with glucose-fructose syrup (GFS-10).

The addition of agricultural waste to culture media significantly increases the yield of riboflavin. This is explained by the presence of fatty acids in the raw material. It is known that riboflavin biosynthesis is stimulated by the addition of unsaturated fatty acids, while saturated ones, on the contrary, inhibit its formation. The ability of the producer to metabolize lipids such as cocoa butter, lecithin, corn oil, olive oil, peanut oil, tall fatty acids is explained by the presence of extracellular lipases [12]. The sunflower cake contains $8-15 \%$ vegetable oil. Most of the fatty acids in sunflower oil are poly- and monounsaturated fatty acids. Therefore, it is expected that sunflower meal will have a positive effect on riboflavin biosynthesis.

The results obtained indicate that the use of sunflower cake in a nutrient medium for the cultivation of $E$. ashbyi F-340 is promising. The oil and fat industry of Ukraine is one of the most powerful branches of the food industry. Accordingly, the production produces large volumes of secondary raw materials, one of which is sunflower cake. In Ukraine, in 2019, 5576 thousand tons of cake and other solid waste were obtained from sunflower seeds [13].

Thus, since Eremothecium ashbyi provides a fairly large yield of riboflavin from crop waste, the development of nutrient media based on such raw materials is a promising and economically profitable direction. However, it should be borne in mind that vegetable raw materials and their waste are very dependent on growing conditions, and the amount of oil remaining in the cake strongly depends on the production conditions. All this can affect the production of riboflavin by the producer. 
The next stage of the study should be the selection of sources of nitrogen and phosphorus for media containing cake, and optimization of the nutrient medium, which is expected to lead to an increase in the level of riboflavin biosynthesis.

\section{Conclusions}

The biosynthetic activity and biomass accumulation by the E. ashbyi F-340 strain on complex nutrient media were studied. It was found that when the producer is cultivated on a medium with glucose-fructose syrup (GFS-10), the level of accumulation of riboflavin is $4-7$ times higher than in other studied media.

The influence of agricultural waste, which includes unsaturated fatty acids that stimulate the production of riboflavin, on the accumulation of riboflavin by the E. ashbyi F-340 strain has been established. In general, the yield of riboflavin on media with plant raw materials is much higher than the control. The best results were obtained on a medium with sunflower meal, the yield of riboflavin is 9.4 times higher than the control.

The growth of the fungus on agar nutrient media with the addition of sunflower oil cake was investigated. It was found that E. ashbyi exhibits a greater biosynthetic ability on a medium containing sunflower cake (the colonies are larger in size, both the colonies themselves and the nutrient medium are more intensely colored) in comparison with the medium without oil cake.

The dependence of the level of accumulation of riboflavin on the concentration of sunflower cake in the nutrient medium has been determined. It was found that with an increase in the concentration of cake to $20 \mathrm{~g} / \mathrm{dm}^{3}$, the level of accumulation of riboflavin increases. The positive effect of oil cake on increasing the concentration of riboflavin, its environmental friendliness and easy accessibility for large-scale cultivation of this producer make the use of sunflower oil cake promising.

\section{References}

1. Abbas, C. A., Sibirny, A. A. (2011). Genetic Control of Biosynthesis and Transport of Riboflavin and Flavin Nucleotides and Construction of Robust Biotechnological Producers. $M i$ crobiology and Molecular Biology Reviews, 75 (2), 321-360. doi: http://doi.org/10.1128/mmbr.00030-10

2. Zhao, G., Dong, F., Lao, X., Zheng, H. (2021). Strategies to Increase the Production of Biosynthetic Riboflavin. Molecular Biotechnology, 63 (10), 909-918. doi: http://doi.org/10.1007/ s12033-021-00318-7
3. Kalingan, A. E., Liao, C. M. (2002). Influence of type and concentration of flavinogenic factors on production of riboflavin by Eremothecium ashbyii NRRL 1363. Bioresource Technology, 82 (3), 219-224. doi: http://doi.org/10.1016/s0960-8524(01)00194-8

4. Pujari, V., Chandra, T. S. (2000). Statistical optimization of medium components for improved synthesis of riboflavin by Eremothecium ashbyii. Bioprocess Engineering, 23 (3), 303-307. doi: http://doi.org/10.1007/PL00009127

5. Cheng, X., Zhou, J., Huang, L., Li, K. (2011). Improved riboflavin production by Eremothecium ashbyii using glucose and yeast extract. African Journal of Biotechnology, 10 (70) doi: http://doi.org/10.5897/AJB11.986

6. Polishchuk, V. Yu., Malaniuk, M. I., Duhan, O. M. (2011) Morfoloho-kulturalni i biosyntetychni vlastyvosti Eremotecium ashbyii Guill. Naukovi visti NTUU «KPI», 3, 74-78.

7. Bampidis, V., Azimonti, G., Bastos, M. D., Christensen, H. Dusemund, B., Durjava, M. F. et. al. (2021). Safety and efficacy of the feed additive consisting of Vitamin B2/Riboflavin produced by Eremothecium ashbyi CCTCCM 2019833 for all animal species. EFSA Journal, 19 (3). doi: http://doi.org/ 10.2903/j.efsa.2021.6462

8. Polishchuk, V., Dugan, O. (2020). Prospects of using glucosefructose syrup in the riboflavin biotechnology. Food Science and Technology, 14 (2). doi: http://doi.org/10.15673/fst.v14i2.1512

9. Dudka, I. A., Vasser, S. P., Ellanskaia, I. A., Koval, E. Z., Gorbik, L. T, Nikolskaia, E. A. et al. (1982). Metody eksperimentalnoi mikologii. Kyiv: Naukova. Dumka, 562.

10. Ostrovskii, Iu. M. (Ed.) (1979). Eksperimentalnaia vitaminologiia. Minsk: Nauka i tekhnika, 552.

11. Shpichka, A. I., Semenova, E. F., Kuznetsova, A. V. (2011) $\mathrm{K}$ voprosu opredeleniia riboflavina $\mathrm{v}$ biotekhnologicheskom syre. Sovremennye problemy nauki i obrazovaniia, 1, 30-32.

12. Ken Ugo, A., Vivian Amara, A., Cn, I., Kenechuwku, U. (2017). Microbial Lipases: A Prospect for Biotechnological Industrial Catalysis for Green Products: A Review. Fermentation Technology, 6 (2). doi: http://doi.org/10.4172/2167-7972.1000144

13. Derzhavna sluzhba statystyky Ukrainy (2021). Available at: http://ukrstat.gov.ua

Nataliia Stetsenko, Department of Industrial Biotechnology and Biopharmacy, National Technical University of Ukraine «Igor Sikorsky Kyiv Polytechnic Institute», Kyiv, Ukraine, ORCID: https://orcid.org/ 0000-0003-2597-2335

$\triangle$ Valentyna Polishchuk, PhD, Associate Professor, Department of Industrial Biotechnology and Biopharmacy, National Technical University of Ukraine «Igor Sikorsky Kyiv Polytechnic Institute», Kyiv, Ukraine, e-mail: polischukvu@gmail.com, ORCID: http://orcid.org/ 0000-0002-1284-584X

Olexiy Dugan, Doctor of Biological Sciences, Professor, Head of Department of Industrial Biotechnology and Biopharmacy, National Technical University of Ukraine «Igor Sikorsky Kyiv Polytechnic Institute», Kyiv, Ukraine, ORCID: https://orcid.org/0000-0002-5646-917X

$\triangle$ Corresponding author 